\section{Commentary: Reconfiguring the airway with the robot to improve patients' quality of life}

\author{
Cameron D. Wright, MD
}

Lazzaro and colleagues ${ }^{1}$ describe a series of robotic tracheobronchoplasties and present intermediate follow-up in 42 patients who underwent operations during 2016 and 2017. There was no mortality or severe morbidity and the patients had improved scores on the St George's Respiratory Questionnaire that were clinically significant. There were no clinically significant differences in spirometry or in the 6-minute walk test. They were selective in who they operated on and rejected more than two-thirds of patients who were believed to initially have significant tracheobronchomalacia (TBM). The cardinal selection criteria were appropriate symptoms, $>90 \%$ airway collapse on awake bronchoscopy, and the absence of significant comorbid lung disease or other disease. Stent trials were not utilized. Lazzaro is a master robotic surgeon and whether or not these results will be translatable to less-facile surgeons is not assured. Hopefully the combination of videos, hands-on events, and proctoring will facilitate the dissemination of this technique, which appears to be less morbid than the thoracotomy approach.

We have much to learn about TBM because tracheal collapse seen on cardiothoracic imaging is fairly common, but most patients are asymptomatic. We must remember the lesson of lung volume reduction surgery when it was popularized before we fully understood the rigorous selection criteria and the principles of operative intervention. Deaths have been reported after TBM repair. ${ }^{2}$ The lack of objective criteria to firmly diagnose TBM and to measure the results of repair has hindered understanding of the role of TBM repair. We must remember the importance of the placebo effect in surgery because when patients are told they will get better after surgery many do with even a sham procedure. Recall the

\footnotetext{
From the Division of Thoracic Surgery, Massachusetts General Hospital, Boston, Mass.

Disclosures: Dr Wright is a consultant for Bayer.

The Journal policy requires editors and reviewers to disclose conflicts of interest and to decline handling or reviewing manuscripts for which they may have a conflict of interest. The editors and reviewers of this article have no conflicts of interest.

Received for publication July 15, 2021; revisions received July 15, 2021; accepted for publication July 16, 2021; available ahead of print July 26, 2021.

Address for reprints: Cameron D. Wright, MD, Division of Thoracic Surgery, Massachusetts General Hospital, Austen 7, 55 Fruit St, Boston, MA 02114 (E-mail: cdwright@mgh.harvard.edu).

J Thorac Cardiovasc Surg 2022;164:287-8

$0022-5223 / \$ 36.00$

Copyright (c) 2021 by The American Association for Thoracic Surgery

https://doi.org/10.1016/j.jtcvs.2021.07.028
}

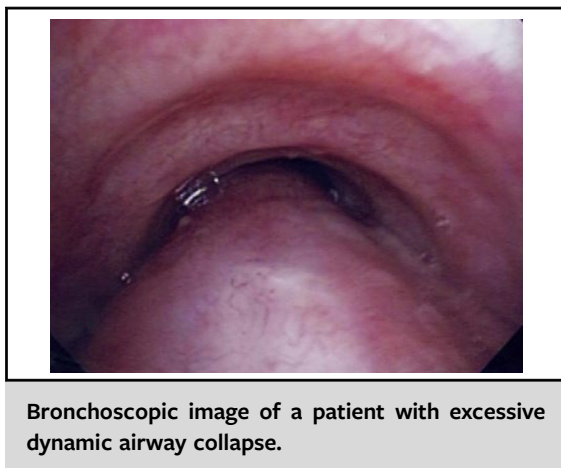

CENTRAL MESSAGE

Robotic TBM repair is an effective procedure to ameliorate symptomatic TBM.

randomized, double-blind sham trial of menisectomy where both cohorts of patients improved to a similar degree. ${ }^{3}$ The symptoms of cough and dyspnea are very common in cohorts of patients like those operated on by Lazzaro and colleagues ${ }^{1}$ and have alternative explanations. These patients were obese (body mass index of 30), 83\% had obstructive sleep apnea, $86 \%$ had gastroesophageal reflux disease, and 52\% had chronic obstructive pulmonary disease and thus had a predisposition for cough and dyspnea. I have always believed that obesity plays a large role in TBM because most patients indeed are obese in surgical series. ${ }^{1,2}$ Not only do obese patients tend to have gastroesophageal reflux disease, which can contribute to years of coughing, but also have low intrathoracic volumes and positive intrathoracic pressures that could contribute to excessive dynamic airway collapse. ${ }^{4}$ Dyspnea is multifactorial and its etiology is very challenging to investigate. We must remember the vast majority of airway obstruction in chronic obstructive pulmonary disease is in the periphery, not the central airways. Why TBM repair would improve dyspnea is unexplained. Robotic TBM repair appears to be an effective procedure to improve symptoms in patients with TBM. More research into excessive dynamic airway collapse and the influence of obesity on respiratory physiology and symptoms needs to be conducted. Hopefully Lazzaro and colleagues will report long-term results in 3 to 5 years so the durability of improvement can be ascertained.

\section{References}

1. Lazzaro RS, Patton BD, Wasserman GA, Karp J, Cohen S, Inra ML, et al. Roboticassisted tracheobronchoplasty: quality of life and pulmonary function assessment on intermediate follow-up. J Thorac Cardiovasc Surg. 2022;164:278-86.

2. Buitrago DH, Majid A, Alape DE, Wilson JL, Parikh M, Kent MS, et al. Singlecenter experience of tracheobronchoplasty for tracheobronchomalacia: perioperative outcomes. Ann Thorac Surg. 2018;106:909-15. 
3. Sihvonen R, Paavola M, Malmivaara A, Itälä A, Joukainen A, Nurmi H, et al. Arthroscopic partial menisectomy versus sham surgery for a degenerative meniscal tear. N Eng J Med. 2013;369:2515-24.
4. Behazin N, Jones SB, Cohen RI, Loring SH. Respiratory restriction and elevated pleural and esophageal pressures in morbid obesity. J Appl Physiol. 2010;108: $212-8$ 